\title{
Nano-akışkan Aşındırıcı Toz Miktarının Yüzey Kalitesine Etkilerinin İncelenmesi
}

\author{
Investigation of the Effects of Nano-fluid Abrasive Powder Amount on the Surface Quality
}

\author{
Ahmet Emre ÖZCAN ${ }^{1} \mathbb{D}$, Mustafa AY ${ }^{2}$ D, Ayhan ETYEMEZ ${ }^{3}$ \\ ${ }^{1}$ Marmara Üniversitesi, Fen Bilimleri Enstitüsü, Makine Mühendisliği Bölümü, 34722, İstanbul, Türkiye, \\ ahmetemreozcan@gmail.com \\ ${ }^{2}$ Marmara Üniversitesi, Teknoloji Fakültesi, Makine Mühendisliği Bölümü, 34722, İstanbul, Türkiye, muay@marmara.edu.tr \\ ${ }^{3}$ Nikken Türkiye, Girne Mah. Irmak Sk., Kü̧̈ükyalı İș Merkezi, A Blok, No:5, 34852, İstanbul, Türkiye, ayhan@nikken.com.tr
}

$\ddot{\mathbf{O z}}$

Bu çalışmada Minimum Miktarda Yağlama (MMY) sistemine katılan aşındıııı toz miktarı ve kesme hızına bağlı olarak işlenmiş yüzeylerdeki yüzey pürüzlülüğündeki değişimler incelenmiştir. Kesme hızı olarak (V:100, 120, 140 ve $160 \mathrm{~m} / \mathrm{dk}$ ) ve kesme yöntemi olarak (kuru, MMY, MMY $+\% 1 \mathrm{Al}_{2} \mathrm{O}_{3}, \mathrm{MMY}+\% 2 \mathrm{Al}_{2} \mathrm{O}_{3}, \mathrm{MMY}+\% 4 \mathrm{Al}_{2} \mathrm{O}_{3}$ ve $\mathrm{MMY}+\% 6 \mathrm{Al}_{2} \mathrm{O}_{3}$ ) kesme parametreleri seçilmiştir. Deney malzemesi olarak yüksek sertliğe ulaşabilmek adına $59 \mathrm{HRC}$ sertliğinde sertleştirilmiş 1.2379 soğuk iş takım çeliği seçilmiş olup, kesici uç olarak ise yüksek sertlikte tornalama işlemlerine dayanıklı olan CBN kesici uç seçilmiştir. Kesme sıvısına katılan aşındıııcı toz olarak $\mathrm{A}_{2} \mathrm{O}_{3}$ nanopartiküller kullanılmış, deney sonrasında yüzey kalitesindeki değişimleri görmek adına MAHR Perthometer M1 yüzey pürüzlülük ölçüm aleti kullanılmıştır. Deney sonuçları incelendiğinde en iyi ortalama yüzey pürüzlülüğüne, kesme hızının $160 \mathrm{~m} / \mathrm{dk}$ ve hacimsel nano-akışkan konsantrasyonunun $\% 4$ olarak uygulandığı deneyde 0,888 m ile ulaşılmıştır. Ortalama yüzey pürüzlülük değerinin en yüksek olduğu deney ise $100 \mathrm{~m} / \mathrm{dk}$ kesme hızında kuru kesme işleminde ortaya çıkmıştır. Farklı parametreler ile yapılan deneyler karşılaştırıldığında kesme hızı ve nano-akışkan konsantrasyonundaki artışın yüzey kalitesine olumlu yönde etkisi olduğu sonucu ortaya çıkmıştır.

Anahtar Kelimeler: Minimum Miktarda Yağlama (MMY), nano-akışkan, yüzey pürüzlülüğü, soğuk iş takım çeliği, nano $\mathrm{A}_{2} \mathrm{O}_{3}$.

\begin{abstract}
In this study, changes in the surface roughness are investigated due to the concentration of nano-fluid and cutting speed. Cutting speed (V $100,120,140$ ve $160 \mathrm{~m} / \mathrm{min}$ ) and cutting method (dry, MQL, MQL $+\% 1 \mathrm{Al}_{2} \mathrm{O}_{3}, \mathrm{MQL}+\% 2 \mathrm{Al}_{2} \mathrm{O}_{3}, \mathrm{MQL}+\% 4 \mathrm{Al}_{2} \mathrm{O}_{3}$ ve MQL $+\% 6 \mathrm{Al} l_{2} \mathrm{O}_{3}$ ) cutting parameters selected. In order to achieve high hardness, hardened 1.2379 cold work tool steel was chosen which is $59 \mathrm{HRC}$ and CBN insert was chosen for the resistant to high hardness. $\mathrm{A}_{2} \mathrm{O}_{3}$ nanoparticles were used as abrasive powder and MAHR Perthometer M1 was used for the measuring of surface roughness. When the results were examined, the best average surface roughness was reached with a rate of $160 \mathrm{~m} / \mathrm{min}$ and volumetric nano-fluid concentration is $\% 4$. The average surface roughness value was worst in the dry cutting process at a cutting speed of $100 \mathrm{~m} / \mathrm{min}$. When the experiments were compared, it was found that the increase in the cutting speed and the concentration of nano-fluids had a positive effect on the surface quality.
\end{abstract}

Keywords: Minimum Quantity Lubrication (MQL), nano-fluid, surface roughness, cold work tool steel, nano $\mathrm{Al}_{2} \mathrm{O}_{3}$.

\section{GİRIŞ}

Hassas ve çok adetli seri üretim işlemini gerçekleştirebilmek için üretilen parçalar yüksek hızda kesme işlemine tabi tutulmalıdır. Yüksek hızda kesme ise beraberinde bir takım problemleri getirmektedir. Bu problemler; takım ömrünün azalması, iş parçası yüzey kalitesinin bozulması ve tezgahın aşırı yüke maruz kalması olarak sıralanabilir. Talaş kaldırma operasyonlarında kesici takım ile iş parçası arasında oluşan yüksek ısı; takım ömrünün azalması ve iş parçası yüzey kalitesinin 
bozulması problemlerinin başlıca kaynağıdır. Bu problemin çözümü için oluşan ısının kesme noktasından ivedilikle uzaklaştırılması gerekmektedir. Oluşan isıyı uzaklaştırmak için kesme noktasına bor yağı vb. soğutma-yağlama sıvıları uygulanarak takım ömründe artış ve iş parçası yüzey kalitesinde düzelme görülmüştür [1]. Geleneksel soğutma sıvılarındaki maliyet artışıyla birlikte çevreye ve insan sağlığına olan olumsuz etkilerinden özellikle talaşlı imalat işlemlerinde yerini MQL (Minimum Quantity Lubrication - Minimum Miktarda Yağlama) uygulamalarına yönelime sebep olmaktadır. MQL, geleneksel ve yüksek hızlarda metalik ve kompozit parçaların işlenmesinde teknolojik, ekonomik ve çevresel faydaları ispatlanmış bir soğutma-yağlama teknolojisidir. MQL' de az miktarda biyo parçalanabilir (geri dönüşümlü) yağ damlacığı ile basınçlı hava karıştırılır ve kesme alanına püskürtülür. Bu durum kesme sıcaklığını ve kesici takım aşınmasını düşürür, yüzey kalitesini artmasına sebep olur [2]. MQL sisteminde kullanılan kesme sivisina $\mathrm{CNT}, \mathrm{C} 60, \mathrm{TiO} 2, \mathrm{Al}_{2} \mathrm{O}_{3}$, MoS2 gibi nano-partiküllerin belirli oranlarda eklenmesi ile oluşan kesme sıvılarına ise nano-akışkan denmektedir. Nano-akışkanların termal iletkenlik özelliklerinin güçlü olması sayesinde kesme noktasında oluşan ısının ortamdan daha verimli olarak uzaklaşması sağlanmaktadır. Ayrıca nano-partiküllerin tribolojik özelliklerine bağlı olarak kesme noktasında iyi bir yağlanma sağlanmakta böylelikle kesme noktasındaki yüzey pürüzlülüğü iyileşmektedir [3].

$\mathrm{Bu}$ çalışmada farklı hacimsel konsanstrasyonlarda $\mathrm{Al}_{2} \mathrm{O}_{3}$ nano-partiküllerin katılmasıyla oluşturulan nano-akışkan, kesme noktasına püskürtülen kesme sıvısı olarak kullanılmıştır. Ayrıca farklı kesme hızları seçilerek yüzey pürüzlülüğüne kesme hızının da etkisi görülmek istenmiştir. Kesme sıvısı olarak farklı hacimsel konsantrasyonlarda nano-akışkan kullanımının yüzey kalitesine etkileri değerlendirilmiştir. Daha önce yapılmış olan $\mathrm{A}_{2} O_{3}$ nano-partikül katkılı nano-akışkanın kullanılmış olduğu deneyler incelendiğinde özellikle yüzey kalitesi üzerine çalışmalar yapıldığı ortaya çıkmaktadır. Lee vd. (2011) nano-elmas ve nano- $\mathrm{Al}_{2} \mathrm{O}_{3}$ partiküllerinin katıldığı nano-akışkan kesme sıvısı kullanılan MQL sisteminin yüzey kalitesi üzerine etkilerini araştırmışlardır. Seçmiş oldukları nano-partiküllerin yağlayıcı özelliklerinin soğutma özelliklerine göre daha ön planda olmasından dolayı daha yüzey kalitesinde iyileşme görüldüğünü ortaya koymuşlardır [3]. Vasu ve Reddy (2011) nano-partikül olarak $\mathrm{Al}_{2} \mathrm{O}_{3}$ ve baz sıvı olarak bitkisel bazlı yağ kullandıkları MQL sistemi ile Inconel 600 alaşımını işlemişlerdir. Farklı hacimsel konsantrasyonda nano-akışkan kullanarak yapmış oldukları deneylerin sonucunda, nano-akışkan konsantrasyon yüzdesinin artmasiyla yüzey kalitesinde iyileşme görmüşlerdir [4]. Mao vd. (2012) sertleştirilmiş
AISI 52100 çeliğini $\mathrm{A}_{2} \mathrm{O}_{3}$ nano-partikül katkılı nano-akışkan kullanarak taşlamışlardır. Kesme sıvısı olarak nano-akışkan kullanımının taşlama noktasındaki sıcaklığı önemli ölçüde düşürdüğünü, yüzey morfolojisini iyileştirdiğini ve yüzey pürüzlülüğünü azalttığını belirtmiş̧lerdir [5]. Hadi ve Atefi (2015) AISI D3 çelik iş parçasını $\mathrm{Al}_{2} \mathrm{O}_{3}$ nano-partikül katkılı nano-akışkan kesme sıvılı MMY sistemi kullanarak frezelemişlerdir. Nano-partikül olarak seçilen $\mathrm{Al}_{2} \mathrm{O}_{3}$ konsantrasyonunun artmasıyla yüzey kalitesinde iyileşme elde etmişlerdir [6].

Yiğit vd. (2014) iş parçası olarak alüminyum alaşımı ve kesme sıvısı olarak $\mathrm{Al}_{2} \mathrm{O}_{3}$ nano-partikül katkılı nano-akışkan seçerek, nano-akışkan kullanımının kesme işlemine etkileri üzerine yapmış oldukları araştırmada nano-akışkan kullanımının yüzey pürüzlülüğüne olumlu yönde etki yaptığını ortaya koymuşlardır [7].

\section{MATERYAL VE YÖNTEM}

Deneylerde JohnFord TC35 marka CNC torna tezgahı kullanılarak 235 HB sertlik değerinde DIN 1.2379 (SVERKER 21) soğuk iş takım çeliği seçilmiştir (Şekil 1). Kesme/makine bıçakları, vidalar/kovanlar, hassas zımbalama kalıpları ve damgalamada kullanılan bu malzeme deneylerde daha yüksek sertlik değerlerinde çalışmak amacıyla 1sıl işleme sokulmuştur. Isıl işlem sonucunda malzeme 59 HRC sertlik değerine ulaşmıştır. Deneylerde kullanılan SVERKER 21 soğuk iş takım çeliği malzemesinin kimyasal özellikleri Tablo 1' de verilmiştir. Deney malzemesinin çap1 $28 \mathrm{~mm}$ ve boyu $150 \mathrm{~mm}$ 'dir.

Tablo 1. SVERKER 21 soğuk iş takım çeliği malzemesi kimyasal özellikleri

\begin{tabular}{|l|l|l|l|l|l|l|l|l|l|}
\hline C & Si & Mn & P & S & Cr & Ni & Mo & V & Cu \\
\hline 1,54 & 0,31 & 0,37 & 0,018 & 0,0006 & 11,5 & 0,22 & 0,74 & 0,73 & 0,06 \\
\hline
\end{tabular}



Şekil 1. JohnFord TC35 CNC torna tezgahı ve deney düzeneği 
Deneylerde DCMW11T304 geometrisine sahip Sumitomo BN600 kalitesinde CBN kesici uç kullanılmıştır. Kesici ucun uç şekli $55^{\circ}$, Serbest açısı $7^{\circ}$, kesme kenar uzunluğu $11 \mathrm{~mm}$, kesici uç kalınlığ $3,97 \mathrm{~mm}$ ve köşe radyüsü 0,4mm'dir (Şekil 2).

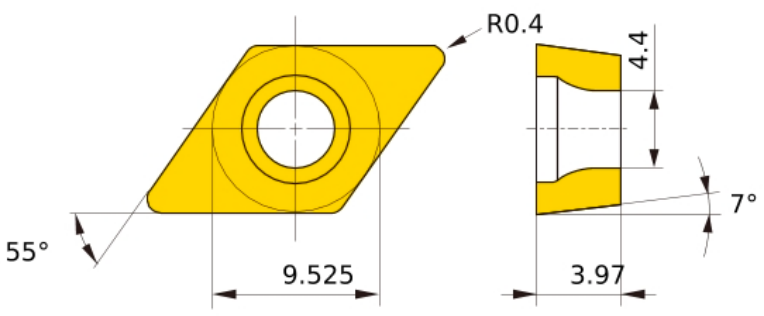

Şekil 2. Deneylerde kullanılan DCMW11T304 kesici uç geometrik şekli [8]

Kesme parametrelerinin belirlenmesinde malzemenin cinsi, tezgah özellikleri ve kesici takım firması katalog değerleri dikkate alınarak Tablo 2'deki kesme parametreleri kullanılarak deneyler gerçekleştirilmiştir.

Tablo 2. Deneylerde kullanılan kesme parametreleri

\begin{tabular}{|l|l|}
\hline PARAMETRE & DEĞER \\
\hline Kesme Yöntemi & $\begin{array}{l}\text { Kuru; MQL; MQL+\%1; MQL+\%2; } \\
\text { MQL+\%4; MQL+\%6 }\end{array}$ \\
\hline Kesme Hızı, V (m/dk) & $100 ; 120 ; 140 ; 160$ \\
\hline İlerleme, f (mm/dev) & 0,1 \\
\hline Kesme Derinliği, a (mm) & 0,1 \\
\hline
\end{tabular}

Deneyin yapılacağ önünde bulundurularak harici MMY uygulamalarına uygun olan Bielomatik MQL 1-Channel System tercih edilmiştir (Şekil 3). Yapılan deneylerde Lubrioil cinsinden yağ kullanılmıştır.

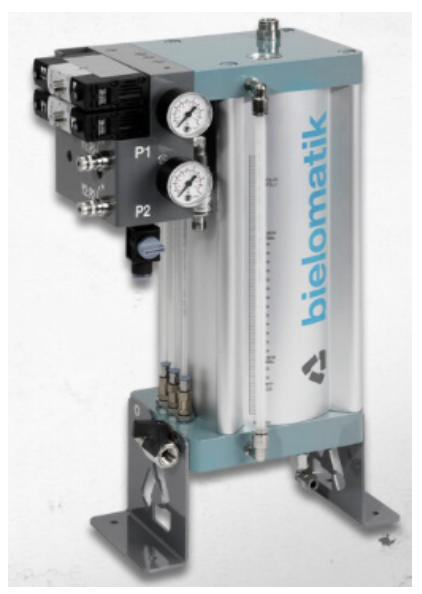

Şekil 3: Bielomatik MQL 1-Channel System [9]
Deneylerde kesme sıvısını nano-akışkan hale getirmek için, kesme sıvısına aşındırıcı toz olarak yüksek sertlik ve yüksek boyutsal stabilite gösteren $\mathrm{Al}_{2} \mathrm{O}_{3}$ tozu katılmıştır. Precisa marka hassas tartı kullanılarak, işleme esnasında kesme sıvısının ağırlıkça \%1, \%2, \%4 ve \%6'sı olacak şekilde kesme sıvısına katılarak 4 farklı nano-akışkan kesme sıvisı oluşturulmuştur. Tablo 3' te deneylerde kullanılan A $l_{2} \mathrm{O}_{3}$ aşındırıcı tozunun teknik özellikleri yer almaktadır [10]. Şekil 4'te $\mathrm{A}_{2} \mathrm{O}_{3}$ aşındırıcı tozunun taramalı elektron mikroskobu (SEM) analizi görüntüsü yer almaktadır [3].

Tablo 3. deneylerde kullanılan $\mathrm{A}_{2} O_{3}$ aşındırıcı tozunun teknik özellikleri [10]

\begin{tabular}{|l|l|}
\hline \multicolumn{2}{|c|}{ Teknik Özellikler } \\
\hline Saflık \% & $99,5+$ \\
\hline Renk & Beyaz \\
\hline Ortalama Partikül Boyutu (nm) & 18 \\
\hline Yüzey Alanı (m2/g) & 140 \\
\hline Is1 Kapasitesi (J/Kg.K) & 890 \\
\hline Yoğunluk ( Kg/m3) & 3900 \\
\hline Morfoloji & Dairesel \\
\hline
\end{tabular}

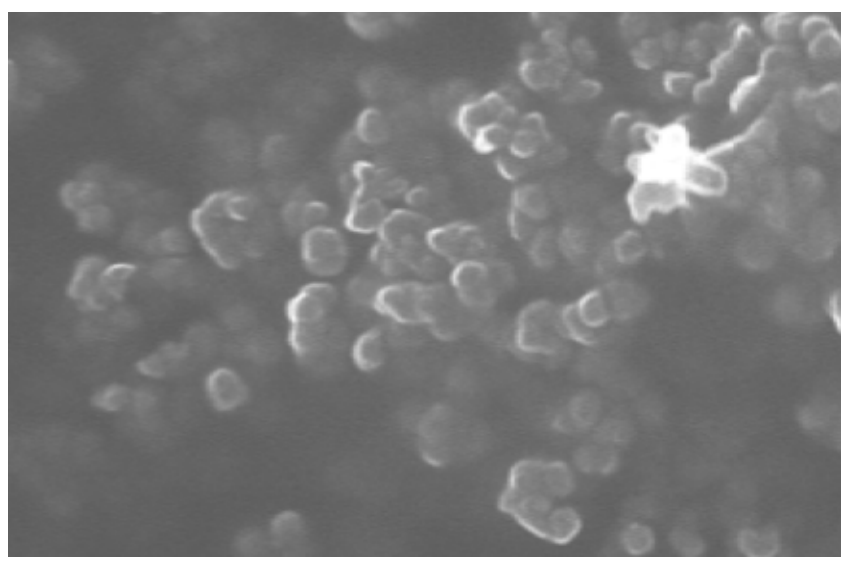

Şekil 4: Deneylerde kullanılan $\mathrm{A}_{2} \mathrm{O}_{3}$ aşındırıcı tozu SEM analizi görünütüsü [3]

Yüzey pürüzlülük değerlerinin ölçümü için DIN, ISO, CNOMO parametrelerinin seri ölçümlerini yapabilen, otomatik ve dinamik kalibrasyon özelliğine sahip, otomatik, 1,75/5,6/17,5 mm tarama boyu seçimli, profil çözünürlüğü $0,012 \mu \mathrm{m}$, entegre termal yazıcilı MAHR Perthometer M1 ölçü aleti kullanılmıştır.

Deney sonrasında iş parçası incelemeleri için; bilgisayar USB girişine bağlantı yapılabilen, 500 kata kadar büyütme özelliğine sahip dijital mikroskop kullanılmıştır. 


\section{BULGULAR VE TARTIŞMA}

Tablo 4'te MQL sistemine katılan farklı miktarlarda aşındirıcı toz, farklı kesme hızları (V 100, 120, 140 ve 160 m/ dk) ve farklı kesme yöntemlerine (kuru, MQL, MQL+\%1 $\mathrm{Al}_{2} \mathrm{O}_{3}, \mathrm{MQL}+\% 2 \mathrm{Al}_{2} \mathrm{O}_{3}, \mathrm{MQL}+\% 4 \mathrm{Al}_{2} \mathrm{O}_{3}$ ve MQL $+\% 6$ $\mathrm{A}_{2} \mathrm{O}_{3}$ ) bağlı olarak gerçekleştirilen deneyler gösterilmiştir. Bu parametrelerle yapılan işleme sonrası oluşan yüzey pürüzlülüğünde ki değişimler Şekil 9-12'deki grafiklerde gösterilmiştir. Şekil 5-8'deki dijital mikroskop altındaki iş parçasının işleme sonrası yapılan incelemelerinde ise kuru kesme ile nano-akışkan kullanılan MQL sisteminin kullanıldığı kesme yöntemi arasındaki yüzey kalitesi farkı görülmektedir.

Aşağıdaki şekiller incelendiğinde; V=100, 120 ve 140 m/ dk kesme hızı için ortalama yüzey pürüzlülük değeri $(\mathrm{Ra})$ ' nın en düşük olduğu kesme yönteminin $\% 6 \mathrm{Al}_{2} \mathrm{O}_{3}$ hacimsel nanoakışkan konsantrasyonuna sahip olduğu deneylerde, $\mathrm{V}=160 \mathrm{~m} / \mathrm{dk}$ kesme hızı uygulandığında ise en iyi yüzey kalitesinin $\% 4 \mathrm{Al}_{2} \mathrm{O}_{3}$ hacimsel nanoakışkan konsantrasyonun uygulandığ 1 deneyde elde edildiği görülmüştür. Kesme hızının 100,120 ve $140 \mathrm{~m} / \mathrm{dk}$ alındığı deneyler incelendiğinde nanoakışkan konsantrasyonun artması yüzey pürüzlülüğüne olumlu etki göstermiştir [6].
Tablo 4. Deney parametreleri; kesme hızı ve kesme yöntemi

\begin{tabular}{|c|c|c|c|c|}
\hline Deney No & Kesme Yöntemi & \begin{tabular}{|l} 
Kesme \\
Hizı (m/ \\
dk)
\end{tabular} & $\begin{array}{l}\text { İlerleme } \\
(\mathrm{mm})\end{array}$ & \begin{tabular}{|l|} 
Talaş \\
Derinliği \\
$(\mathrm{mm})$
\end{tabular} \\
\hline Deney 1 & Kuru Kesme & \multirow{6}{*}{100} & \multirow{6}{*}{0,1} & \multirow{6}{*}{0,1} \\
\hline Deney 5 & MQL & & & \\
\hline Deney 9 & MQL + \%1 Al2O3 & & & \\
\hline Deney 13 & $\mathrm{MQL}+\% 2 \mathrm{Al} 2 \mathrm{O} 3$ & & & \\
\hline Deney 17 & $\mathrm{MQL}+\% 4 \mathrm{Al} 2 \mathrm{O} 3$ & & & \\
\hline Deney 21 & MQL + \%6 Al2O3 & & & \\
\hline Deney 2 & Kuru Kesme & \multirow{6}{*}{120} & \multirow{6}{*}{0,1} & \multirow{6}{*}{0,1} \\
\hline Deney 6 & MQL & & & \\
\hline Deney 10 & $\mathrm{MQL}+\% 1 \mathrm{Al} 2 \mathrm{O} 3$ & & & \\
\hline Deney 14 & $\mathrm{MQL}+\% 2 \mathrm{Al} 2 \mathrm{O} 3$ & & & \\
\hline Deney 18 & $\mathrm{MQL}+\% 4 \mathrm{Al} 2 \mathrm{O} 3$ & & & \\
\hline Deney 22 & $\mathrm{MQL}+\% 6 \mathrm{Al} 2 \mathrm{O} 3$ & & & \\
\hline Deney 3 & Kuru Kesme & \multirow{6}{*}{140} & \multirow{6}{*}{0,1} & \multirow{6}{*}{0,1} \\
\hline Deney 7 & MQL & & & \\
\hline Deney 11 & MQL + \%1 Al2O3 & & & \\
\hline Deney 15 & $\mathrm{MQL}+\% 2 \mathrm{Al} 2 \mathrm{O} 3$ & & & \\
\hline Deney 19 & $\mathrm{MQL}+\% 4 \mathrm{Al} 2 \mathrm{O} 3$ & & & \\
\hline Deney 23 & $\mathrm{MQL}+\% 6 \mathrm{Al} 2 \mathrm{O} 3$ & & & \\
\hline Deney 4 & Kuru Kesme & \multirow{6}{*}{160} & \multirow{6}{*}{0,1} & \multirow{6}{*}{0,1} \\
\hline Deney 8 & MQL & & & \\
\hline Deney 12 & $\mathrm{MQL}+\% 1 \mathrm{Al} 2 \mathrm{O} 3$ & & & \\
\hline Deney 16 & $\mathrm{MQL}+\% 2 \mathrm{Al} 2 \mathrm{O} 3$ & & & \\
\hline Deney 20 & $\mathrm{MQL}+\% 4 \mathrm{Al} 2 \mathrm{O} 3$ & & & \\
\hline Deney 24 & $\mathrm{MQL}+\% 6 \mathrm{Al} 2 \mathrm{O} 3$ & & & \\
\hline
\end{tabular}

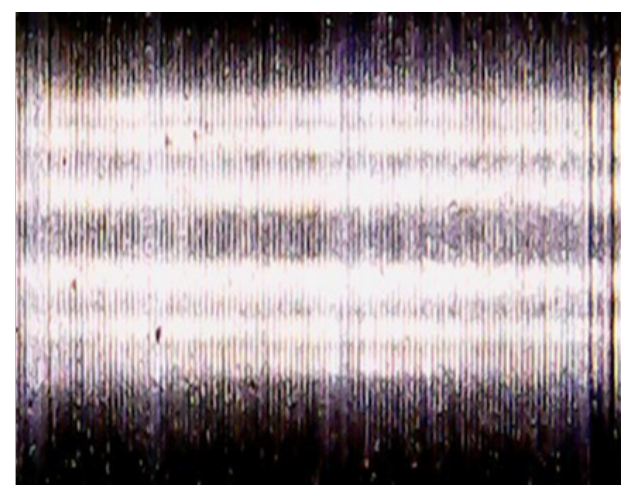

(Deney 21)

(Deney 1)

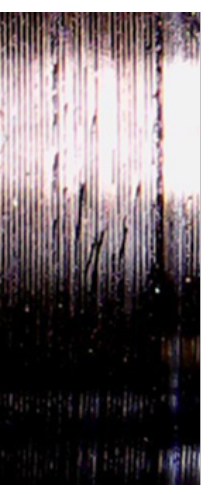

政 


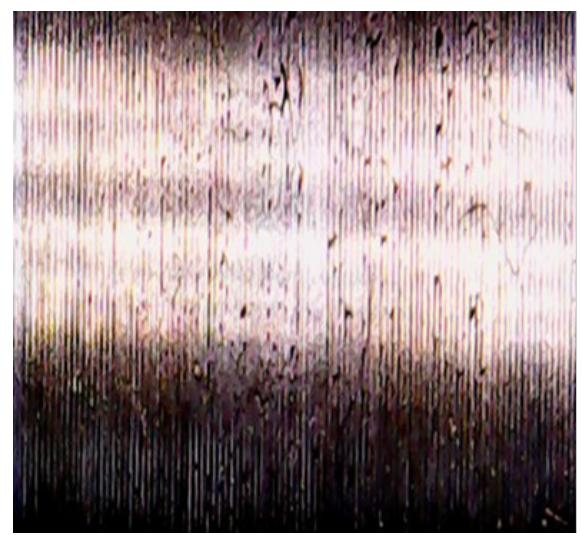

(Deney 2)

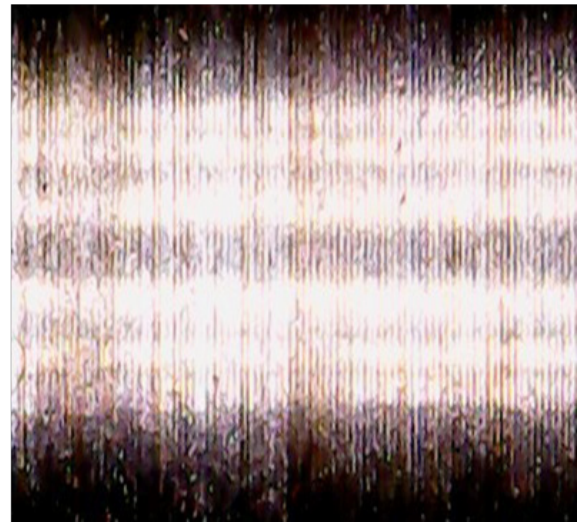

(Deney 22)

Şekil 6: $\mathrm{V}=120 \mathrm{~m} / \mathrm{dk}$ kesme hızında kuru kesme ve MQL+\%6 $\mathrm{A}_{2} \mathrm{O}_{3}$ nano-akışkanın kullanıldığı iş parçası yüzeylerinin dijital mikroskop altında incelenmesi

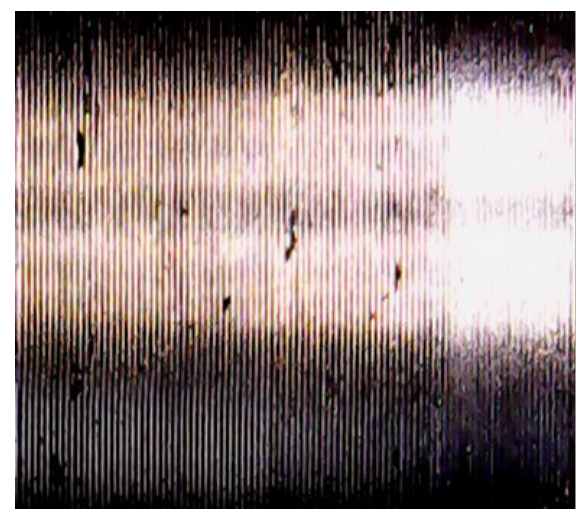

(Deney 3)

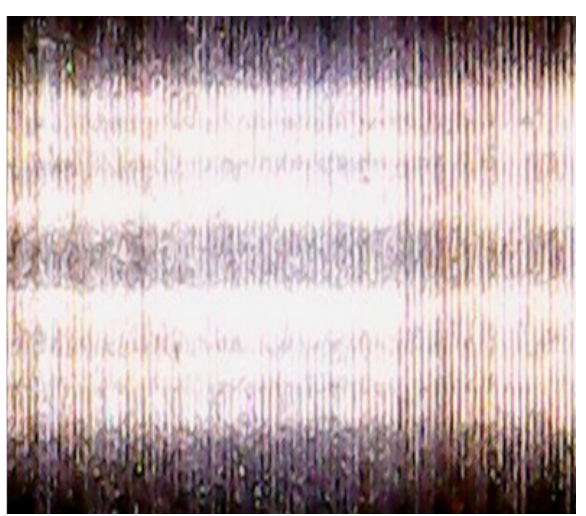

(Deney 23)

Şekil 7. $\mathrm{V}=140 \mathrm{~m} / \mathrm{dk}$ kesme hızında kuru kesme ve MQL+\%6 $\mathrm{l}_{2} \mathrm{O}_{3}$ nano-akışkanın kullanıldığ iş parçası yüzeylerinin dijital mikroskop altında incelenmesi

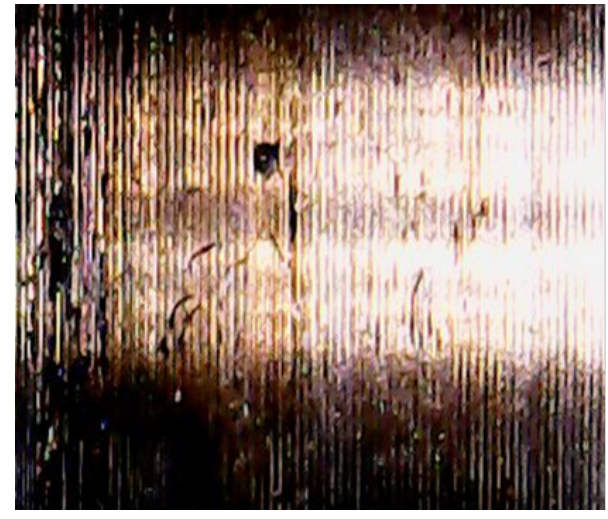

(Deney 4)

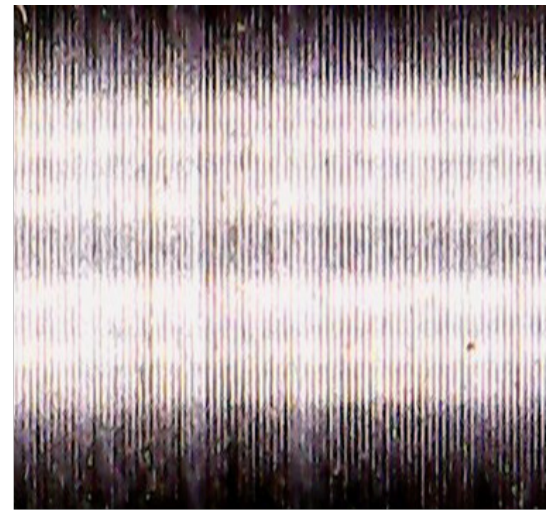

(Deney 20)

Şekil 8: $\mathrm{V}=160 \mathrm{~m} / \mathrm{dk}$ kesme hızında kuru kesme ve $\mathrm{MQL}+\% 4 \mathrm{Al}_{2} \mathrm{O}_{3}$ nano-akışkanın kullanıldığ iş parçası yüzeylerinin dijital mikroskop altında incelenmesi 
$\mathrm{V}=100,140$ ve $160 \mathrm{~m} / \mathrm{dk}$ kesme hizlarında kuru kesmeye göre MQL sisteminin uygulanmasının yüzey kalitesine olumlu yönde etki ettiği görülmektedir. $\% 1 \mathrm{Al}_{2} \mathrm{O}_{3}$ hacimsel konsantrasyonda nano-akışkan kullanılan deneylerde ise $\mathrm{V}=100$ ve $120 \mathrm{~m} / \mathrm{dk}$ kesme hızlarında yüzey kalitesinde iyileşme görülürken $\mathrm{V}=140$ ve $160 \mathrm{~m} / \mathrm{dk}$ kesme hızlarında yüzey kalitesinde bozulma görülmüştür. 140 ve $160 \mathrm{~m} / \mathrm{dk}$ kesme hızına çıkıldı ğında $\% 1 \mathrm{Al}_{2} \mathrm{O}_{3}$ konsantrasyonunun kullanıldığı soğutma sistemi uygulamasının yüzey kalitesine yeterli şekilde etki etmediği görülmektedir. Hacimsel $\mathrm{A}_{2} \mathrm{O}_{3}$ konsantrasyonunun $\% 2$ ' nin üzerine çıkmas1 ile birlikte yüzey kalitelerinde iyileşme görülmüş olup, $\% 4$ $\mathrm{Al}_{2} \mathrm{O}_{3}$ hacimsel konsantrasyona sahip olan $160 \mathrm{~m} / \mathrm{dk}$ kesme hızında yapılan deney en iyi ortalama yüzey pürüzlülüğü değerini vermiştir. Yukarıda bahsedilen literatür çalışmalarından da görüleceği üzere $\mathrm{Al}_{2} \mathrm{O}_{3}$ nano-partiküllerin katıldığ 1 nano-akışkan kullanılan deneyler yüzey kalitesine olumlu yönde etki göstermiştir.

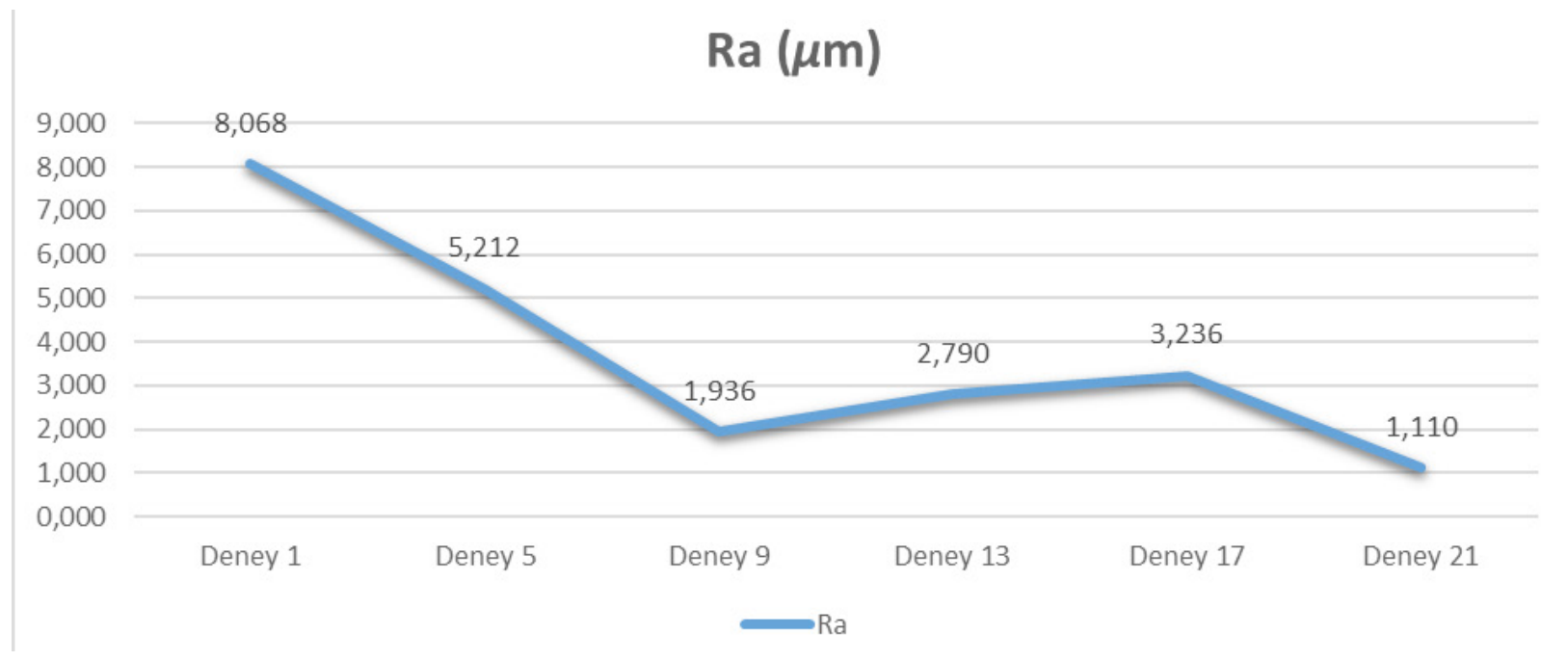

Şekil 9: Kesme hızı V=100 m/dk için kesme yöntemine bağlı olarak elde edilen ortalama yüzey pürüzlülük (Ra) değerleri değişimi

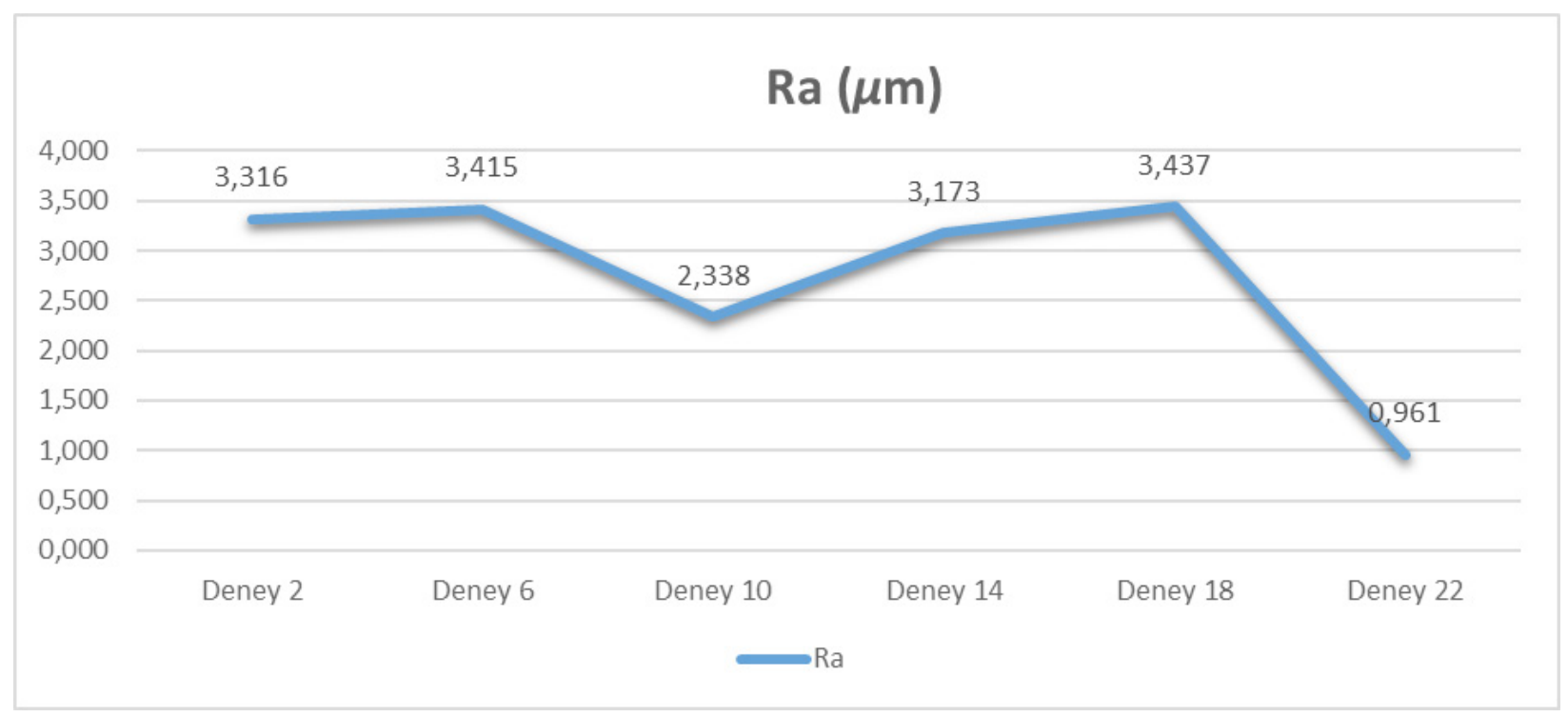

Şekil 10: Kesme hızı V=120 m/dk için kesme yöntemine bağlı olarak elde edilen ortalama yüzey pürüzlülük (Ra) değerleri değişimi 


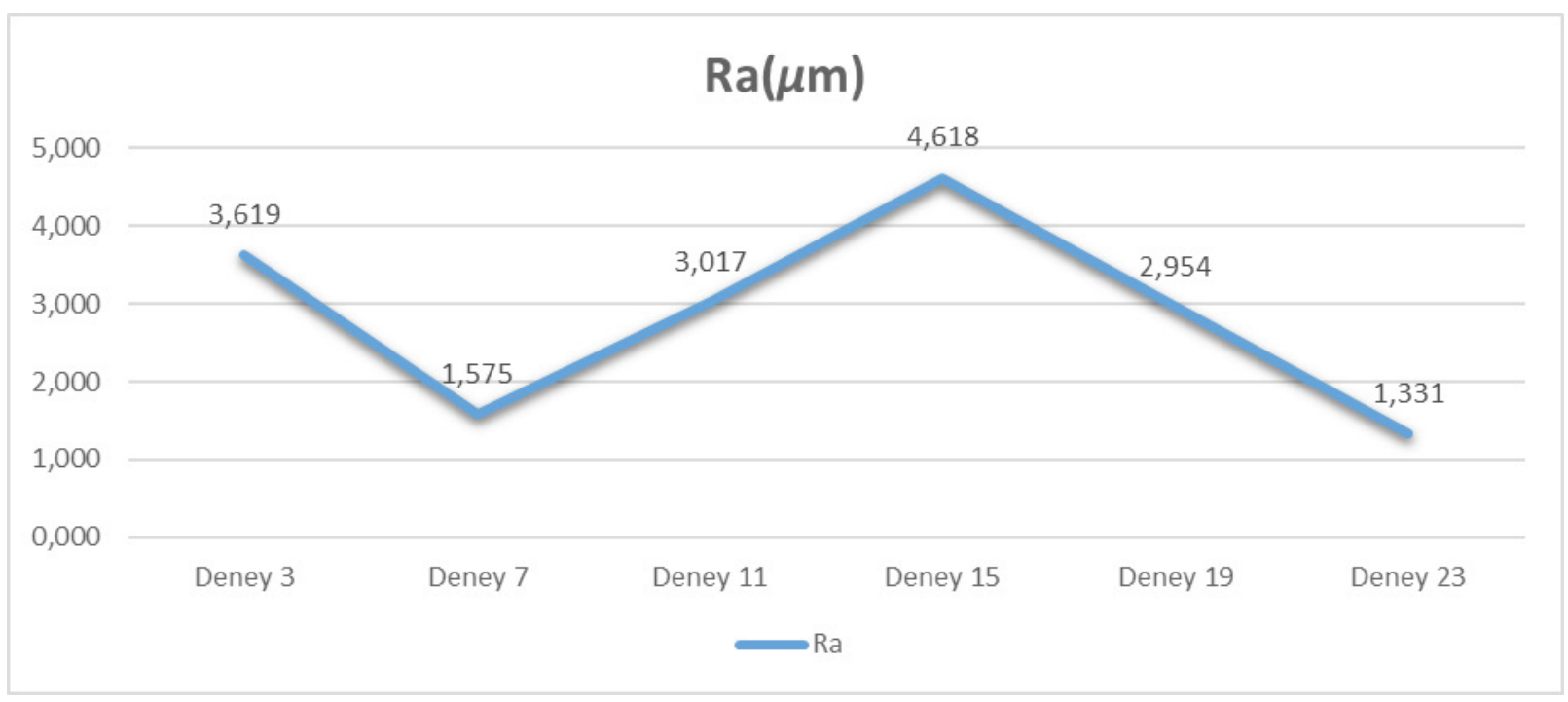

Şekil 11: Kesme hızı V=140 m/dk için kesme yöntemine bağlı olarak elde edilen ortalama yüzey pürüzlülük (Ra) değerleri değişimi

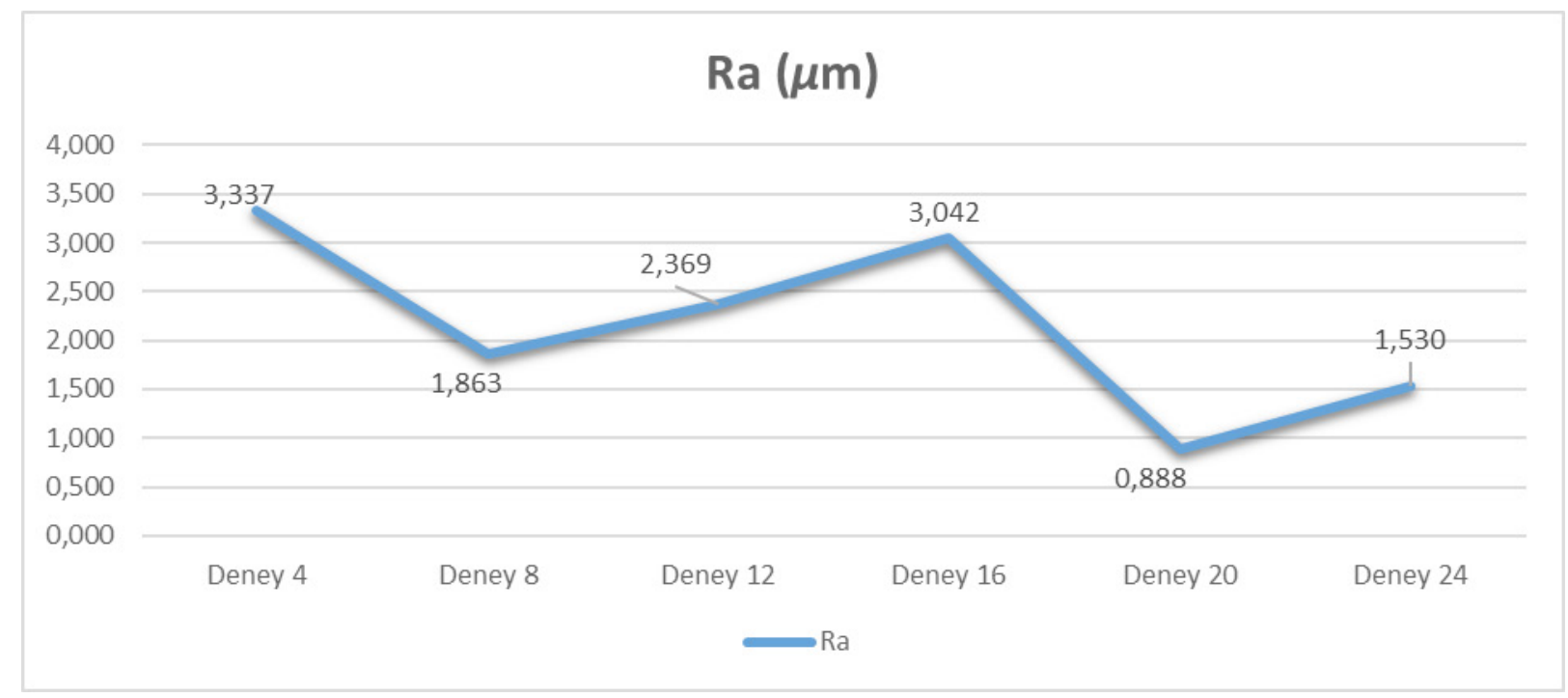

Şekil 12: Kesme hızı V=160 m/dk için kesme yöntemine bağlı olarak elde edilen ortalama yüzey pürüzlülük (Ra) değerleri değişimi

\section{SONUÇLAR}

1.2379 sertleştirilmiş soğuk iş takım çeliği deney numunelerinin CNC torna tezgahında, farklı kesme hızları ve MMY sistemine katılan farklı aşındırıcı toz miktarları ile işılenmesi sonucunda elde edilen deney sonuçları aşağıdaki gibi özetlenmiştir:

1- Bütün parametrelerin sabit tutulup sadece kesme hızının artırılmasının yüzey kalitesine olumlu yönde etki ettiği görülmüştür.
2- En iyi ortalama yüzey pürüzlülüğüne $(\mathrm{Ra})$, kesme hızının $160 \mathrm{~m} / \mathrm{dk}$ ve nanoakışkan konsantrasyonunun $\% 4$ olarak uygulandığı deneyde $0,888 \mu \mathrm{m}$ ile ulaşılmıştır. Ortalama yüzey pürüzlülük değerinin en yüksek olduğu deney ise $100 \mathrm{~m} / \mathrm{dk}$ kesme hızında kuru kesme işleminde ortaya çıkmıştır. Bu iki sonuç göz önüne alındığında kesme hızındaki artışın ve nanoakışkan kullanılan MMY sisteminin yüzey kalitesine olumlu yönde etkisi olduğu sonucuna varılmıştır. 
3- Kuru kesme ile MMY sistemi karşılaştırıldığında, MMY sistemi kullanılan deneylerde ortalama yüzey pürüzlülüğünde azalma görülmüştür. MMY sistemi ile nano-akışkan katkılı MMY sistemi karşılaştıııldığında ise nano-akışkan katkılı MMY sisteminin daha iyi yüzey kalitesi oluşturduğu görülmüştür.

4- Kesme sıvısına katılan aşındırıcı toz olarak seçilen A $l_{2} \mathrm{O}_{3}$ nano-partiküllerinin konsantrasyonunun yüzey pürüzlülüğü üzerinde gösterdiği olumlu etki, MMY sisteminin ve katılan aşındırıcı toz miktarının önemini kanıtlamış, insan sağlığı ve çevre kirliliği açısından tercih edilmesi gerektiğini ortaya koymuştur.

\section{Teşekkür}

Marmara Üniversitesi Bilimsel Araştırma Projeleri Birimi tarafindan desteklenen FEN-E-090.517.0273 numaralı proje kapsamında alınan ekipmanlar ile deneyler yapılmıştır.

\section{Kaynaklar}

[1] Yıldırım, Ç. V., Kıvak, T. ve Erzincanlı, F. (2015). Minimum Miktarda Yağlama Tekniğinin Delme ve Taşlama Operasyonlarındaki Uygulamaları Üzerine Bir Derleme. 6. Ulusal Talaşlı İmalat Sempozyumu, İstanbul, 247-263.

[2] Gürbüz, H., Baday, Ş., \& Gönülaçar, Y. E. (2017). Minimum Miktarda Yağlamanın Frezeleme İşlemleri Üzerine Etkisinin Araştırılması: Derleme. Batman Üniversitesi Yaşam Bilimleri Dergisi, 7(2/2), 59-78..

[3] Lee, P. H., Nam, J. S., Li, C., \& Lee, S. W. (2012). An experimental study on micro-grinding process with nanofluid minimum quantity lubrication (MQL). International Journal of Precision Engineering and Manufacturing, 13(3), 331338..

[4] Vasu, V., \& Pradeep Kumar Reddy, G. (2011). Effect of minimum quantity lubrication with $\mathrm{A} 12 \mathrm{O} 3$ nanoparticles on surface roughness, tool wear and temperature dissipation in machining Inconel 600 alloy. Proceedings of the Institution of Mechanical Engineers, Part N: Journal of Nanoengineering and Nanosystems, 225(1), 3-16.

[5] Mao, C., Tang, X., Zou, H., Huang, X. ve Zhou, Z. (2012). Investigation of Grinding Characteristic using Nanofluid Minimum Quantity Lubrication. International Journal of Precision Engineering and Manufacturing, 13 (10): 1745-1752.

[6] Hadi, M. ve Atefi, R. (2015). Effect of Minimum Quantity Lubrication with Gamma-A12O3 Nanoparticles on Surface Roughness in Milling AISI D3 Steel. Indian Journal of Science and Technology, 8 (S3): 130-135.

[7] Yiğit, R., Yıldırım, S. ve Çelik E. (2013). The Improvement of Metal Cutting Processing Using A12O3 Nanoparticles. Afyon Kocatepe University Journal of Science and Engineering, 14 (2014): 441-445.

[8] Mitsubishi Materials Web Catalogue, http://www.mitsubishicarbide.net/mhg/ enuk/turning_inserts/no _srs/20042879 (Eylül 2018)

[9] Bielomatik MQL Systems, https://www.bielomatik.com/fileadmin/Dokumente/EN/ Schmiersysteme/ Brochure _MQL_ EN_0316KL.pdf. (Aralık 2018)

[10] Alüminyum oksit nanopartikül kimyasal özellikleri, http:// nanografi.com.tr/al2o3-aluminyum-oksit-nanopartikul-gama-18nm-safl-k-99-5-hidrofilik. (Aralık 2018) 